\title{
Impact of Working Experience on Image Perception and Image Evaluation Approaches in Stroke Imaging: Results of an Eye-Tracking Study
}

\author{
Einfluss der Arbeitserfahrung auf die Wahrnehmung und \\ Auswertung radiologischer Datensätze in der Schlaganfall- \\ Bildgebung: Ergebnisse einer Eye-Tracking-Studie
}

Authors

Sara Kammerer ${ }^{1}$, Christoph Schülke², Martin Dominik Leclaire², Wolfram Schwindt², Aglae Velasco Gonzalez², Tarek Zoubi², Walter Heindel ${ }^{2}$, Boris Buerke ${ }^{2}$

Affiliations

1 Department of Neuroradiology, University-Hospital Frankfurt, Frankfurt, Germany

2 Department of Clinical Radiology, University-Hospital Münster, Münster, Germany

Key words

visual perception, radiologists, health care quality, computerized tomography, stroke, acute

received 20.08.2018

accepted 14.12.2018

Bibliography

DOI https://doi.org/10.1055/a-0826-5056

Published online: 31.1.2019

Fortschr Röntgenstr 2019; 191: 836-844

(c) Georg Thieme Verlag KG, Stuttgart · New York

ISSN 1438-9029

Correspondence

Dr. Sara Kammerer

Klinikum der Johann-Wolfgang-Goethe-Universität

Frankfurt, Institut für Neuroradiologie, Schleusenweg 2-16,

60528 Frankfurt am Main, Germany

Tel.: ++49/69/63015462

Sara.Kammerer@kgu.de

\section{ZUSAMMENFASSUNG}

Hintergrund Höhere Raten von verpassten Pathologien, verursacht durch mangelnde Berufserfahrung oder systematische Suche, legen nahe, dass ein methodischer Ansatz zur radiologischen Analyse erlernt werden kann. Ziel dieser Studie ist es daher, die Effizienz verschiedener Prinzipien des Screenings von Schlaganfall-CTs auf zerebrovaskuläre Erkrankungen zwischen Radiologen und Neuroradiologen mit unterschiedlichen Erfahrungsniveaus in Bezug auf die Berufserfahrung zu untersuchen.

Methoden Anonymisierte CT-Bilder von 20 Patienten mit Verdacht auf einen Schlaganfall wurden 12 Radiologen mit unterschiedlicher Berufserfahrung individuell präsentiert. Währenddessen wurde ihre Fixationsposition durch ein EyeTracking-System erfasst. Für die statistische Analyse wurden die Interobserver-Variabilität und die Genauigkeit der Läsionserkennung unter Berücksichtigung der individuellen Berufserfahrung bewertet.

Ergebnisse Die Sensibilität des Betrachters hängt von seiner beruflichen Erfahrung ab, die auch durch eine systematische Beobachtungsreihenfolge und die Kenntnis des Krankheitsverlaufs bestimmt wird. Die Dauer der Augenfixation von unerfahrenen Bildbefundern war bei auffälligen Befunden deutlich länger, während erfahrene Radiologen eher klinisch relevante Regionen fixierten. Die Verweildauer der okulären Fixation bei wichtigen pathologischen Befunden unterschied sich nicht signifikant zwischen diesen Erfahrungsgruppen.

Schlussfolgerung Unsere Ergebnisse zeigen, dass erfahrene Radiologen die Zahl der verpassten Befunde durch einen systematischen Ansatz und eine gezielte Untersuchung wichtiger Regionen reduzieren. Durch die Sensibilisierung für die Analyse von CT-Bildern in systematischen Mustern scheinen Ärzte aller Erfahrungsstufen in der Lage zu sein, ihre Leistung zu verbessern.

\section{Kernaussagen:}

- Erfahrene Radiologen verbessern die Erkennungsraten durch gezielte Inspektion klinisch wichtiger Regionen.

- Erfahrene Radiologen reduzieren den Zeitaufwand für die Analyse durch gezielte visuelle Aufmerksamkeit.

- Alle Erfahrungsstufen verbessern ihre Leistung durch die systematische Analyse von CT-Bildern.

\section{ABSTRACT}

Purpose Higher rates of missed pathologies, caused by a lack of professional experience or systematic search, suggest that a methodical approach to radiological analysis can be learned. Thus, the aim of this study is to investigate the efficiency of different principles of screening stroke CTs for cerebrovascular diseases between radiologists and neuroradiologists with different levels of experience in relation to professional experience. 
Methods A set of anonymous CT images of 20 patients, with a suspected stroke, was individually presented to 12 radiologists with different levels of professional experience. Meanwhile, their fixation position was recorded by an eye-tracking system. For statistical analysis, the interobserver variability and accuracy of lesion detection were evaluated, taking the individual level of professional experience into account.

Results The sensitivity of the observer depends on the professional experience, also determined by a systematic observation sequence and knowledge of the course of the disease. The duration of eye fixation with inexperienced assessors was significantly longer for conspicuous findings, while experienced assessors were more likely to fix clinically relevant regions. The retention time of ocular fixation in important pathological findings did not differ significantly between those groups.

Conclusion Our results indicate that experienced radiologists are reducing the number of missed findings through a systematic approach and targeted inspection of important regions. Through raising the awareness of analyzing CT images in systematic patterns, physicians at all levels of experience seem to be able to improve their performance.

\section{Key points:}

- Experienced radiologists improve detection rates through targeted inspection of clinically important regions.

- Experienced radiologists reduce time spent on analysis through focused visual attention.

- All levels of experience improve their performance by analyzing CT images systematically.

\section{Citation Format}

- Kammerer S, Schülke C, Leclaire MD et al. Impact of Working Experience on Image Perception and Image Evaluation Approaches in Stroke Imaging: Results of an Eye-Tracking Study. Fortschr Röntgenstr 2019; 191: 836844

\section{Introduction}

One of the essential skills of a radiologist is to identify imaging patterns and their corresponding pathologies. The expertise of radiologists grows as their professional experience broadens not only due to increased specialist knowledge, but also due to continuously improving proficiency in pattern recognition. While specialist knowledge can be expanded as a result of clinical practice and appropriate reading matter, the processes that help to continuously improve such pattern recognition have not yet been fully understood. The higher speed at which findings are identified by an experienced radiologist is probably attributable to his familiarity with potential patterns, permitting a scan to be reviewed much faster. The lack of experience of younger radiologists frequently leads to less focused approaches in respect to differentiating major from minor diagnostic findings. Major findings predominantly included vessel occlusions of brain supplying arteries, one cerebral sinus venous thrombosis and one randomly depicted pulmonary embolism. Minor diagnostic findings included vascular aberrations, preexisting postischemic defects or pulmonary findings, such as pulmonary nodules, infiltrates or a pneumothorax and a struma. The precise extent to which the approach of experienced versus less experienced radiologists differs remains unclear. Recommendations on best practices for examining radiographic images as well as for optimizing the detection of findings could be defined based on such deliberations.

Eye tracking is a method that is already widespread in miscellaneous research fields, especially economics, and has been used, for example, in studies for analyzing marketing campaigns [1 4]. The method automatically tracks the movement of the eyeball and position of the pupil while an image or screen is being viewed. Furthermore, it records the duration that the eye focuses on the relevant areas of the image, without disturbing the assessor. This method can therefore be used to determine which areas of an image were viewed and for how long, as well as which areas were potentially completely ignored [5].

To potentially provide younger colleagues with specific training and optimize observation patterns, awareness of efficient techniques for examining scans is of high importance [6]. Thus, the aim of this study was to record observation patterns of radiologists when reviewing stroke CTs, depending on their professional experience, and to evaluate the detection/recognition of findings. In addition, the influence of right or wrong clinical information on the reader's focus was observed.

\section{Materials and Methods}

\section{Subjects}

A total of 12 radiologists, with 6 of them working as residents ( $1-5$ years of working experience) and 6 as radiologic specialists (3 were general radiologic senior physicians, the other 3 were additionally trained as neuroradiologic specialists), were included for the analysis of image data sets. The average length of working experience was 8 years.

For evaluation, the radiologic assessors used a regular workstation prepared with an eye tracker on the bottom of the regular radiologic computer screen. The blinded CT data sets were presented to the assessors through a study supervisor. These assessors were asked to analyze images according to their normal working pattern. Meanwhile, their eye movements were recorded with the eye tracker.

In terms of potential interference to eye tracking records, 4 participants had normal vision or contact lenses and 8 of them had corrected-to-normal vision via glasses. Each reader had to analyze 20 blinded and randomly presented stroke CT data sets including non-enhanced CT (NECT), CT angiography (CTA) and CT perfusion (CTP). Diagnostic CT imaging examinations were 
indicated by suspected stroke. In order to simulate comparable clinical reporting conditions in the best manner, clinical information was given prior to image analysis and the time span per image analysis was limited to a maximum of 10 minutes. To avoid artifacts during fixation measurements and to precisely measure the time needed for appraisal, pathologies were recorded by the study supervisor through a think aloud concept.

\section{Measurement of the diagnostic accuracy}

The image diagnoses used as the basis for the treatment were used as the "gold standard" of the available findings in order to subsequently evaluate how many of these findings were actually found by the assessors and to compare the diagnostic accuracy of experienced and less experienced assessors.

\section{Measurement of duration of image reading}

The maximum time span permitted for image analysis was restricted to 10 minutes. To simulate the clinical setting of CT image reading, the gaze estimation methods are based on real-time image processing videos recording the reader's fixation. This allows retrospective analysis of the time needed by the radiologists to read data sets.

\section{Order of evaluation of orientations and reconstructions}

Additionally, by analyzing these real-time image processing videos, the order of the image evaluation preferred by the individual assessors for diagnosis was analyzed retrospectively.

\section{Regions of interest}

Furthermore, video analysis allows for investigation of regions of interest (ROIs) that were defined manually for all patients by encircling every pathologic area in every cross-sectional view. For 6 randomly chosen patients, the proportionate time of focusing the ROls was measured, as well as the time until the assessor's first fixation of an ROI, depending on the examiner's working experience.

Institutional review board approval was granted to retrospectively analyze anonymized CT data using eye tracking and to record the data of the radiologic assessor.

\section{Eye tracking device}

The utilized device (Tobii X2 - 60 Eye Tracker, Tobii Technology $A B$, Danderyd, Sweden) was based on corneal reflection recorded unobtrusively by a tracker located below the screen. Prior to the recording, a calibration was performed for each participant to correlate the fixation area on the screen to the coordinates. The distance between the participant and the monitor was kept constant at $65 \mathrm{~cm}$ by means of a mark on the floor. Gaze data were recorded for both eyes with a sampling rate of $60 \mathrm{~Hz}$. Eye gaze coordinates were acquired every $16.7 \mathrm{~ms}$. The fixation areas and durations were determined using a predefined computerized classification algorithm, working with overlays. Consequently, heat maps of the assessor's fixation areas, scan paths and the fixation of dedicated ROls were generated. Due to the volumetric ima- ging, ROls had to be defined manually for every cross-sectional view containing a pathology.

\section{MSCT acquisition}

The examinations were performed using a 256-slice CT scanner (Somatom ${ }^{\circledR}$ Definition FLASH, Siemens AG, Medical Solutions, Forchheim, Germany). For i.v. contrast administration (Ultravist $^{\circledR}-370$, Bayer Schering Pharma, Leverkusen, Germany), according to the local standardized scanning protocols, $40-60 \mathrm{~mL}$ are injected followed by a $25-\mathrm{mL}$ saline bolus chaser, using a constant injection rate of $>4 \mathrm{~mL} / \mathrm{s}$.

Images were obtained at a tube voltage of $120 \mathrm{kV}$ and $200 \mathrm{mAs}$, using a special dose-modulation template (CARE dose4DTM, Siemens AG, Medical Solutions, Forchheim, Germany) to reduce the radiation exposure [7]. Data sets were reconstructed at a slice thickness of $1.5 \mathrm{~mm}$ with a reconstruction increment of $0.6 \mathrm{~mm}$. For CTP, dynamic scanning was performed at a $66-\mathrm{sec}-$ ond biphasic cine series using the following standardized parameters: 80 kVp, 200 mA, 1-second rotation time, 1 image per second for 40 seconds with 9 additional images at a rate of one every third second, as used in the clinical routine [8]. For evaluation, different color-coded maps (cerebral blood volume (CBV), cerebral blood flow (CBF), mean transit time (MTT), and time-to-peak (TTP)) were generated.

\section{Statistical analysis}

Statistical analysis was performed using SAS (Version 9.3 for Windows, SAS Institute Inc., Cary, NC, USA). Inferential statistics were intended to be exploratory (generating hypotheses) instead of confirmatory and were interpreted accordingly. Hence, p-values were interpreted according to Fisher, by assessing the metric weight of evidence against the respective null hypothesis of no effect. P-values were considered significant if $\leq 0.05$ and highly significant if $\leq 0.01$. Standard descriptive statistical analyses were performed.

Categorical variables are described as absolute and relative frequencies.

\section{Results}

For every required case, reconstructions of acquired CT data were technically feasible and assessable. Neuroradiologic reports of diagnostic findings, which were the basis for the treatment, were defined as the "gold standard" of pathologic findings. Objects to be detected are categorized as main findings causing the neurologic symptoms, e. g. early signs of cerebral ischemia, acute arterial occlusions, dissection of the cervical arteries, cerebral venous sinus thrombosis or findings suspicious for tumor, and as secondary findings without relevance with respect of the suspected stroke, including preexisting cerebral infarctions or preexisting vessel pathologies like aneurysms or atherosclerosis, cervical pathologies that are recorded in the cervical angiography of brain-supplying vessels, like struma or in one case a cervical hematoma, or thoracic pathologies containing pulmonary diseases like pneumo- 
- Table 1 Detection rates.

- Tab. 1 Detektionsraten.

detection rates in relation to available findings

\section{overall pathologies}

main findings

secondary findings pathologies identified

\begin{tabular}{|l|l|l|l|}
\hline a: residents & b: senior physicians & c: general radiologists & d: neuro-radiologists \\
\hline 0.68 & 0.60 & 0.61 & 0.60 \\
\hline 0.81 & 0.79 & 0.81 & 0.76 \\
\hline 0.56 & 0.44 & 0.43 & 0.45 \\
\hline
\end{tabular}

Listed above is the ratio of the findings detected from all available findings (overall pathologies), additionally subdivided into main and secondary findings. The above (in b) depicted ratio of the findings detected from all available findings (overall pathologies) is specified as senior physicians with (d: neuroradiologists) or without a neuroradiological focus (c: general radiologists).

thorax, pulmonary infiltrates or pleural effusions, a cardiomegaly in one patient and subcutaneous emphysema.

\section{Overall and itemized diagnostic accuracy}

Overall and itemized diagnostic concordance with consensus with respect to main or secondary findings and considering the working experience are detailed in $>$ Table 1 . Secondary or incidental findings in this context are all findings that have no connection to the symptoms or primary disease (examples are aneurysms, pleural effusions, struma nodosa, etc.). Diagnostic concordance varied in relation to professional experience, while no relevant differences in the detection rates of the main findings as a function of working experience could be observed (residents detected 203 of 252 pathologies ( Table 1 ) and senior physicians observed 196 of 249 pathologies ( $\triangleright$ Table 1; the difference results from the fact that a participant did not evaluate two data sets). Furthermore, the general radiologic specialists observed 102 of 126 pathologies and the neuroradiologic specialists detected 94 of 123 findings ( $\vee$ Table 1 ; again, the difference can be explained by the lack of interpretation of two data sets by a test person). However, with respect to secondary findings, greater differences between experienced and less experienced assessors were observed. Of the 282 secondary findings, the resident physicians noticed 158 ( $0.56 \%$; - Table 1$)$, while the senior physicians only noticed 122 of 278 ( $0.44 \%$; Table 1 ; again, the difference can be explained by the lack of interpretation of two data sets by a test person) secondary findings. With regard to their professional focus, general radiologic specialists observed 60 of 141 secondary findings and neuroradiologic specialists mentioned 62 of 137 secondary pathologies ( $\triangleright$ Table 1 ; again, the difference can be explained by the lack of interpretation of two data sets by a test person).

\section{Overall and itemized duration of image reading}

The overall time needed to read all available images showed a highly significant difference between resident physicians and senior physicians, as shown in $>$ Table 2, • Fig. 1. The average time resident physicians spent for reading the available images was 5:41.5 minutes:seconds, whereas senior physicians averaged
4:12 minutes:seconds (neuroradiologic specialists needed 4:6.7 minutes:seconds and general radiologists needed an average time of 4:17.1 minutes:seconds to read the available radiologic images). A more detailed consideration is presented in the three right-hand columns in $\mathbf{~ T a b l e ~} 2$. However, it reveals no significant differences between the proportionate times needed in regard to the computer tomographic angiographies with amounts of $58 \%$ of the overall inspection times by residents and $53 \%$ by senior physicians (52\% for neuroradiologic specialists and $53 \%$ for general radiologic specialists). By considering the proportionate times of reading different orientations of the $\mathrm{CT}$ angiographies, transverse image orientations are mostly used by all groups. Nevertheless, additional viewing of coronal orientations of CT angiographies could be observed slightly more often in neuroradiologists, compared to less specialized readers ( $\triangleright$ Table 2 ).

\section{Order of evaluation of orientations and reconstructions}

By means of "screen recordings", the order of evaluating the images the individual assessors preferred for their image reporting could retrospectively be analyzed. Mostly, probands tended to start reporting by inspecting the brain in NECT before altering to the bone window setting, the CT perfusion or CT angiography in different orientations. Less experienced assessors more often changed between the different reconstructions and image series with an average number of alternations of 8.1 (43.1 in relation to total inspection time), compared to 6.2 average alternations of senior physicians, resulting in 40.6 in relation to their total inspection time (6.1 with and 6.4 without neuroradiologic specialization).

\section{Regions of interest}

The final investigation included the separate evaluation of the main pathologies in 6 cases. The observed pathologies included a thrombosis of the basilar artery, an occlusion of the internal carotid artery, a double-sided occlusion of the MCA, a dissection of the aorta, an occlusion of ipsilateral ICA and MCA and an occlusion of vertebral and basilar artery. For all patients, regions of interest (ROIs) were defined manually by encircling the area around 
- Table 2 Reading times.

- Tab. 2 Befundungsdauer.

\begin{tabular}{|l|l|l|l|l|l|}
\hline $\begin{array}{l}\text { time to read available } \\
\text { images in seconds }\end{array}$ & $\begin{array}{l}\text { average time } \\
\text { per data set }\end{array}$ & $\begin{array}{l}\text { standard } \\
\text { deviation }\end{array}$ & $\begin{array}{l}\text { reading time in } \\
\text { transverse orientation }\end{array}$ & $\begin{array}{l}\text { reading time in } \\
\text { sagittal orientation }\end{array}$ & $\begin{array}{l}\text { reading time in } \\
\text { coronal orientation }\end{array}$ \\
\hline all assessors & 297.1 & 113.2 & 0.48 & 0.03 & 0.04 \\
\hline resident physicians & 341.5 & 109.8 & 0.51 & 0.04 & 0.03 \\
\hline senior physicians & 252.0 & 98.2 & 0.45 & 0.02 & 0.05 \\
\hline $\begin{array}{l}\text { general radiologic } \\
\text { senior physicians }\end{array}$ & 246.7 & 98.2 & 0.42 & 0.03 & 0.07 \\
\hline $\begin{array}{l}\text { neuroradiologic senior } \\
\text { physicians }\end{array}$ & 257.1 & 98.7 & 0.48 & 0.01 & 0.04 \\
\hline
\end{tabular}

The evaluation in the two columns on the left was based on the average time required for analyzing a case in seconds by all radiologists and according to the subgroups of assistant doctors and senior physicians (with and without neuroradiological focus). The three columns on the right show the percentage of time required to analyze the different section orientations (transverse, sagittal and coronal) of the total observation time.

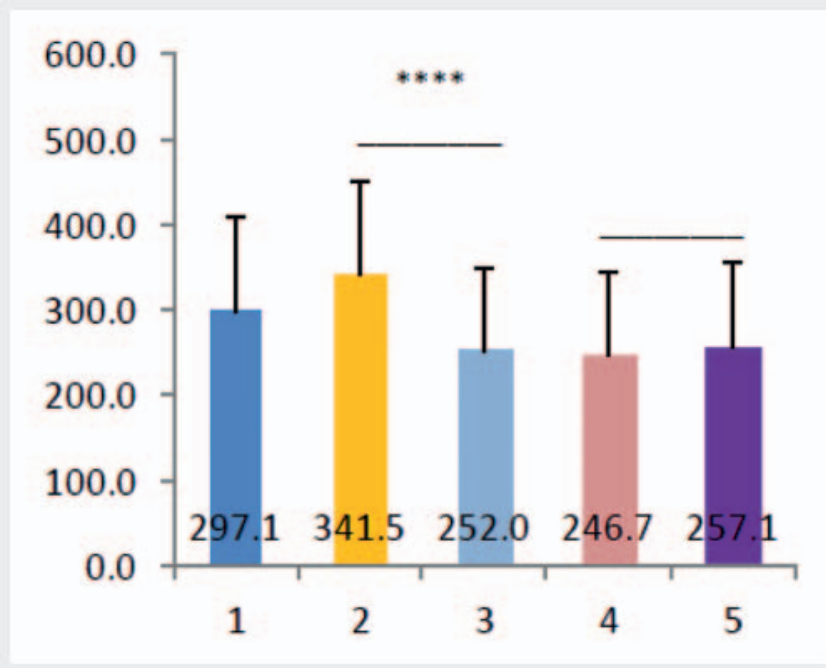

- Fig. 1 Average diagnosis duration per case for all assessors. Above shown is the average total diagnostic time in milliseconds per case for all subjects (1), assistant doctors (2), senior physicians (3), senior physicians with (4) and without a neuroradiological focus (5). A significant difference (marked by ${ }^{* * *}$ ) between assistant and senior physicians $(p<0.0001)$ is shown, with both values being within the standard deviation of the respective other value. There was no significant difference between the subgroups of senior physicians.

- Abb. 1 Durchschnittliche Diagnosedauer pro Fall für alle Befunder. Oben dargestellt ist die durchschnittliche Gesamtdiagnostikzeit in Millisekunden pro Fall für alle Probanden (1), Assistenzärzte (2), Oberärzte (3), Oberärzte mit (4) und ohne neuroradiologischen Schwerpunkt (5). Ein signifikanter Unterschied (markiert mit ****) zwischen Assistenzärzten und Oberärzten $(p<0,0001)$ wird angezeigt, wobei beide Werte innerhalb der Standardabweichung des jeweils anderen Wertes liegen. Es gab keinen signifikanten Unterschied zwischen den Untergruppen der Oberärzte.
- Table 3 Duration of the fixation of the ROI.

- Tab. 3 Dauer der Fixation einer „ROI“.

\begin{tabular}{|l|l|}
\hline $\begin{array}{l}\text { duration of the fixation } \\
\text { of the ROI }\end{array}$ & $\begin{array}{l}\text { ratio of duration of the fixation } \\
\text { to total inspection time }\end{array}$ \\
\hline all assessors & 0.128 \\
\hline resident physicians & 0.127 \\
\hline senior physicians & 0.128 \\
\hline $\begin{array}{l}\text { general radiologic senior } \\
\text { physicians }\end{array}$ & 0.138 \\
\hline $\begin{array}{l}\text { neuroradiologic senior } \\
\text { physicians }\end{array}$ & 0.119 \\
\hline
\end{tabular}

In 6 patients out of the 20 patients whose $\mathrm{CT}$ data sets were included, ROI-specific evaluations were also generated to specifically analyze the duration of the fixation of the diagnostic findings marked with ROI (in seconds), pro rata to the duration of the overall inspection time.

the pathology in every cross-sectional view containing it ( $\triangleright$ Fig. 2). For recording and evaluation of the recorded data, the Studio Capture software (Tobii Technology) was used. The proportionate time of focusing the ROls was measured and a quotient to the total inspection time was calculated ( $\triangleright$ Table 3 ). Furthermore, we evaluated the duration until the reader's first fixation of the ROI, depending on the working experience ( $\triangleright$ Table 4). While no significant differences of the relative time period to focus the region of interest between the individual groups based on experience could be observed, less time is needed regarding the time duration until first focusing of the ROI particularly by neuroradiologic specialists to detect the predominantly neurologic pathologies. Neuroradiologic specialists detected the pathology most rapidly (average 1:28.2 minutes:seconds; - Table 4). However, general radiologic specialists on average 


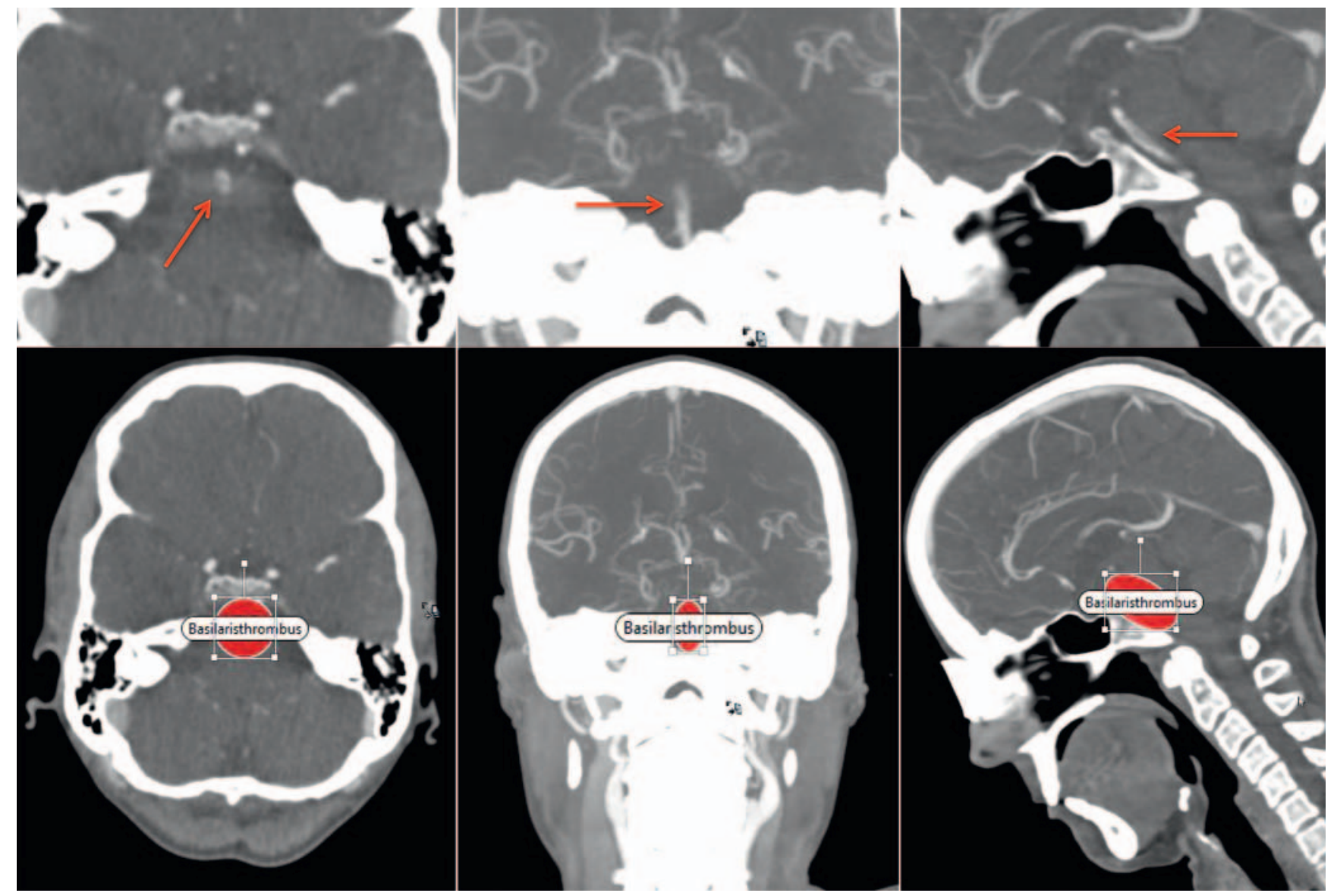

- Fig. 2 ROI labeling. In the present CT angiography scan, a thrombus within the lumen of the basilar artery can be seen (upper row); in the lower row this pathology is labelled with an ROI in all 3 planes (examplarily in one slice each, whereby this labeling must be carried out in all slices of all planes in which the pathology can be seen) in order to analyze visual fixation of the ROI.

- Abb. 2 Beschriftung ROI. In der vorliegenden CT-Angiografie ist ein Thrombus im Lumen der Basilar-Arterie zu sehen (obere Reihe); in der unteren Reihe ist diese Pathologie in allen 3 Ebenen mit einer ROI markiert (beispielhaft in einer Schicht, wobei diese Markierung in allen Schichten aller Ebenen, in denen die Pathologie zu sehen ist, durchgeführt werden muss), um die visuelle Fixierung des ROI zu analysieren.

- Table 4 Time until first fixation of the ROI.

- Tab.4 Zeit bis zur ersten Fixierung einer „ROI“.

\begin{tabular}{|l|l|}
\hline $\begin{array}{l}\text { time until first fixation } \\
\text { of the ROI }\end{array}$ & $\begin{array}{l}\text { time until first fixation } \\
\text { of the ROI (median in } \\
\text { seconds) }\end{array}$ \\
\hline all assessors & 108.6 \\
\hline resident physicians & 114.8 \\
\hline senior physicians & 93.9 \\
\hline $\begin{array}{l}\text { general radiologic senior physi- } \\
\text { cians }\end{array}$ & 114.7 \\
\hline
\end{tabular}

neuroradiologic senior physicians

88.2

Additionally, in these 6 patients out of the 20 patients whose CT data sets were included, ROI-specific evaluations were generated in order to specifically analyze the time until the first fixation of the ROI-labelled findings (in seconds), compared to the reference time (therefore the average duration of senior physicians in seconds is set as the reference). required 1:54.7 minutes:seconds and residents 1:54.8 minutes: seconds until first fixation of the ROI (54). Nonetheless, these results do not achieve the predefined level of significance $(p=0.06)$.

Comparing the time period utilized to inspect the different contrast phases (non-contrast CT, CT angiography and CT perfusion), the ratios indicate that neuroradiologic specialists prefer to survey the pathology on non-enhanced CTs (42\% of total time used to survey the ROI in NECT versus $32 \%$ on CT perfusion and $25 \%$ on CT images; $>$ Table 5), whereas the residents, like general radiologists, prefer the observation of the pathologies on CTA images (general radiologists prefer the observation on CTA with $51 \%$ of total time versus $30 \%$ on CT perfusion and $19 \%$ on NECT; residents prefer the survey on CTA with $47 \%$ of total time compared to $21 \%$ on CT perfusion and $32 \%$ on NECT; - Table 5 ).

\section{Discussion}

In the clinical routine, neuroradiologic CT imaging in the case of suspected stroke using unenhanced brain CT, CT angiography of the supra-aortic vessels and CT perfusion represents a common 
Table 5 Duration of the fixation of the ROI in different contrast administrations.

- Tab.5 Dauer der Fixation einer „ROI“ in den verschiedenen Kontrastierungsphasen.

\begin{tabular}{|l|l|l|l|l|}
\hline $\begin{array}{l}\text { duration of the fixation of the ROI itemized to different con- } \\
\text { trast administrations in relation to total inspection time }\end{array}$ & $\begin{array}{l}\text { fixation of the ROI } \\
\text { in CT perfusion }\end{array}$ & $\begin{array}{l}\text { fixation of the ROI } \\
\text { in non-contrast CT }\end{array}$ & $\begin{array}{l}\text { fixation of the ROI } \\
\text { in CT angiography }\end{array}$ \\
\hline all assessors & 0.26 & 0.31 & 0.43 \\
\hline resident physicians & 0.21 & 0.32 & 0.47 \\
\hline senior physicians & 0.31 & 0.31 & 0.38 \\
\hline general radiologic senior physicians & 0.30 & 0.19 & 0.51 \\
\hline neuroradiologic senior physicians & 0.32 & 0.42 & 0.25 \\
\hline
\end{tabular}

Moreover, in these 6 of the 20 included CT datasets, ROI-specific evaluations were generated in order to specifically analyze the duration of the ROI-labelled findings in the different contrast administrations (non-enhanced CT, CT angiography and CT perfusion) in seconds, related to the overall time needed to inspect each dataset.

method to explore the pathology causing the symptoms. CT angiography offers detailed information about the vascular system and CT perfusion provides valuable information regarding the brain's vascular physiology [9-11]. Consequently, radiologists read hundreds of sections of imaging in the case of a suspected acute ischemic stroke. Compared to reading a single static radiograph, requirements differ substantially in terms of understanding the cognitive and perceptual processes of interpreting volumetric data sets like CT stroke imaging. The visual search for lesions is a process that has been shown to be mainly acquired rather than innate and that depends on the working experience.

To evaluate the observations of the assessors, this method has so far been applied for the radiologic fields of mammography and projection of the chest or the extremities [12-15]. Only a few studies of multislice images have been conducted to date. Furthermore, no studies were conducted for more complex scenarios such as multimodal diagnostic imaging, for example in the event of medical emergencies such as strokes [16-19].

Several theories regarding potential sources of error in the detection of pathologies have been proposed. For instance, the holistic model for the searching strategy applied by radiologists when reading mammograms, the theory about the satisfaction of search errors or the assumption of a global perceptual process [20 - 22]. Research conducted with eye tracking technology has revealed a connection between the visual dynamics and cognitive processes.

Whether radiologists are explicitly aware of the details or not, training has taught them to focus attention more efficiently on items with high probability of interest [23].

Some investigations even differentiated between the 3 different phases in which errors of image reporting can occur. This includes the search, the recognition and the cognitive process to identify a lesion [24].

\section{Overall and itemized diagnostic accuracy}

The study focused on the accuracy of search as one of the major pitfalls, revealing an overall detection rate between $76 \%$ and $81 \%$, with slight differences correlated to the level of education. Espe- cially with regard to the accuracy of the recognition of secondary findings in the group of senior physicians, it should be mentioned that the lesions were partially fixed but not mentioned. In the context of this study setting, a clear distinction cannot be made between missed pathologies and incidental findings not mentioned due to their lack of clinical relevance.

\section{Overall and itemized times of image reading}

Kundel and Nodine described a diagnostic accuracy of $70 \%$ when presenting chest radiographs to radiologists for $200 \mathrm{msec}$. According to Kundel et al., the visual search of radiographic images occurs in two steps: starting with the initial rapid primary "global" response, taking place during the first 40-200 ms, followed by a second "systemic scan", allowing for accurate object recognition using foveal vision [25]. Systematic viewing is a technique whereby anatomical areas are inspected in a fixed order to ensure complete inspection of the images. In order to imitate the clinical setting of reporting as accurately as possible and to include the assumed "systematic scan" into our analysis, we determined a period of 10 minutes. This allows a detailed examination.

Furthermore, we investigated the detection error in greater detail by deconstructing the assessor's image analysis into the following time ranges: the time until first detection of the pathology, the duration of the fixation of the pathology and the proportionate time of observation in different contrast phases (NECT, CTA and CT perfusion). To the best of the author's knowledge, previous studies have not investigated these aspects of image analysis. Neuroradiologic specialists detected the pathology most rapidly, which could be explained by their superior experience. However, the relative time needed to fix the pathology does not reveal significant differences between the groups. In this case, this could be attributed to the common pathologies, which are easy to assess, even for less experienced assessors.

The differences between the proportions of analyzing images separated into different contrast phases could also be explained by the neuroradiologists superior experience, resulting in less time required to analyze the CTA in relation to the total time of 
inspection. However, the lack of experience leads residents to spend proportionally more time on CTA image analysis, compared to the total time.

Visual search is an integral part of the radiologist's interpretation procedure, but the precise search requirement varies considerably with individual clinical situations. Such as the purpose of the examination and the radiologist's prior knowledge about the patient. In many cases, a free search is required, meaning that the radiologist needs to search the complete data set for any abnormalities, whereas the clinical situation may require him to focus on specific anatomical areas [26]. Although we specified clinical information and observed fixation of clinically important regions in reference to the symptoms more rapidly in the group of experienced readers, the influence of clinical information about the patient was not specifically part of this study and is to be confirmed in further investigations. Our results reveal that observer's sensitivity depends on work experience due to systematic scanning of important areas combined with knowledge about the course of disease. The areas of missed pathologies mostly included secondary findings without connection to the primary disease or a lack of methodical approach of the inspection. Thus, eye tracking can potentially be used to improve the learning curve of teaching residents for radiologic inspection by teaching them to follow the eye-gaze patterns of expert radiologists.

A limitation is the use of the final radiological reports to define the major and minor findings. While major findings are most likely be reported, minor findings might not be. Additionally, the sample size was restricted both by limited availability of participants and the time required for the individual evaluations. Furthermore, general radiologists in our institute are very well trained in crosssectional imaging diagnostics of neuroradiological findings, as there is no separation between general and neuroradiological findings in cross-sectional imaging, which can explain the small differences in performance between general radiologists and neuroradiologists.

In conclusion, our results suggest that the experience of radiologic physicians improves the detection of major findings by looking at CT images more systematically with inspection of anatomical areas in a fixed order, as well as an intentional scan of clinically important regions (like areas causing identifiable symptoms), taking into account the individual clinical symptoms.

Visual attention was more focused in the case of the experienced physicians and often less time was needed.

However, all levels of experience seem to be able to improve their performance by analyzing CT images systematically.

\section{Conclusion}

- Our results suggest that the experience of radiologic physicians improves the detection of major findings by looking at CT images more systematically, meaning inspection of anatomical areas in a fixed order to ensure full coverage, as well as an intentional scan of clinically important regions (like areas causing identifiable symptoms), taking into account the individual clinical symptoms.
- Visual attention was more focused in the case of the experienced physicians and often less time was needed.

\section{CLINICAL RELEVANCE OF THE STUDY}

- Understanding how radiologic expertise is developed may allow training regimes and consequently the performance of all groups of experienced and inexperienced radiologists can be improved.

- The speed and thus efficiency of expression as well as the quality of detection rates can be improved.

- Pitfalls can be avoided with knowledge of the approaches.

\section{Conflict of Interest}

The authors declare that they have no conflict of interest.

\section{References}

[1] Duchowski A. A breadth-first survey of eye-tracking applications. Behavior Research Methods, Instruments, \& Computers 2002; 34: 455 470. doi:10.3758/BF03195475

[2] Schmeißer DR, Behrendt C, Singer B. Werbewirkung messen und optimieren. Planung und Analyse 2005; 6: 2-8

[3] Brusch M, Sand N, Stüber E. Wirkungsmessung der Online-Werbung von Nonprofit Organisationen-Eine Analyse der visuell aufgenommenen Werbeinformation und deren Glaubwürdigkeit. Proceedings of the 9th International Conference Marketing Trends. Venice, 2010

[4] Geise S, Brettschneider F. Die Wahrnehmung und Bewertung von Wahlplakaten: Ergebnisse einer Eyetracking-Studie. Information-Wahrnehmung-Emotion; Springer; 2010: 71-95

[5] Duchowski A. Eye tracking methodology: Theory and practice; Springer Science \& Business Media; 2007

[6] Venjakob AC, Mello-Thoms CR. Review of prospects and challenges of eye tracking in volumetric imaging. Journal of medical imaging (Bellingham, Wash) 2016; 3: 011002. doi:10.1117/1.jmi.3.1.011002

[7] Hundt W, Rust F, Stabler A et al. Dose reduction in multislice computed tomography. Journal of computer assisted tomography 2005; 29: 140 147

[8] Hesselmann V, Niederstadt T, Dziewas R et al. Reperfusion by combined thrombolysis and mechanical thrombectomy in acute stroke: effect of collateralization, mismatch, and time to and grade of recanalization on clinical and tissue outcome. AJNR American journal of neuroradiology 2012; 33: 336-342. doi:10.3174/ajnr.A2746

[9] de Lucas EM, Sanchez E, Gutierrez A et al. CT protocol for acute stroke: tips and tricks for general radiologists. Radiographics: a review publication of the Radiological Society of North America, Inc 2008; 28: 1673 1687. doi:10.1148/rg.286085502

[10] Knauth M, von Kummer R, Jansen $\mathrm{O}$ et al. Potential of $\mathrm{CT}$ angiography in acute ischemic stroke. AJNR American journal of neuroradiology 1997; 18: $1001-1010$

[11] Saba L, Anzidei M, Piga M et al. Multi-modal CT scanning in the evaluation of cerebrovascular disease patients. Cardiovascular diagnosis and therapy 2014; 4: 245 -262. doi:10.3978/j.issn.2223-3652.2014.06.05

[12] Barrett JR, Johns NG, Dwyer SJ 3rd et al. Unobtrusive evaluation of mammographer's eye movements during diagnosis of mammograms. Radiographics: a review publication of the Radiological Society of North America, Inc 1996; 16: 167-172. doi:10.1148/radiographics.16.1.167 
[13] Kundel HL, Nodine CF, Krupinski EA et al. Using gaze-tracking data and mixture distribution analysis to support a holistic model for the detection of cancers on mammograms. Academic radiology 2008; 15: 881 886. doi:10.1016/j.acra.2008.01.023

[14] Kundel HL, Nodine CF, Toto L. Searching for lung nodules. The guidance of visual scanning. Investigative radiology 1991; 26: 777-781

[15] Hu CH, Kundel HL, Nodine CF et al. Searching for bone fractures: a comparison with pulmonary nodule search. Academic radiology 1994; 1: $25-32$

[16] Helbren E, Halligan S, Phillips P et al. Towards a framework for analysis of eye-tracking studies in the three dimensional environment: a study of visual search by experienced readers of endoluminal CT colonography. The British journal of radiology 2014. doi:10.1259/bjr.20130614

[17] Mallett S, Phillips P, Fanshawe TR et al. Tracking Eye Gaze during Interpretation of Endoluminal Three-dimensional CT Colonography: Visual Perception of Experienced and Inexperienced Readers. Radiology 2014; 273: 783 - 792. doi:10.1148/radiol.14132896

[18] Phillips P, Boone D, Mallett S et al. Method for tracking eye gaze during interpretation of endoluminal 3D CT colonography: technical description and proposed metrics for analysis. Radiology 2013; 267: 924-931. doi:10.1148/radiol.12120062

[19] Matsumoto H, Terao Y, Yugeta A et al. Where do neurologists look when viewing brain $\mathrm{CT}$ images? An eye-tracking study involving stroke cases. PloS one 2011; 6: e28928. doi:10.1371/journal.pone.0028928
[20] Samuel S, Kundel HL, Nodine CF et al. Mechanism of satisfaction of search: eye position recordings in the reading of chest radiographs. Radiology 1995; 194: 895 - 902. doi:10.1148/radiology.194.3.7862998

[21] Berbaum KS, Franken EA Jr, Dorfman DD et al. Satisfaction of search in diagnostic radiology. Investigative radiology 1990; 25: 133-140

[22] Kundel HL, Nodine CF, Conant EF et al. Holistic component of image perception in mammogram interpretation: gaze-tracking study. Radiology 2007; 242: 396 - 402. doi:10.1148/radiol.2422051997

[23] Drew T, Evans K, Võ MLH et al. Informatics in Radiology: What Can You See in a Single Glance and How Might This Guide Visual Search in Medical Images? Radiographics: a review publication of the Radiological Society of North America, Inc 2013; 33: 263 - 274. doi:10.1148/rg. 331125023

[24] Waite S, Kolla S, Jeudy J et al. Tired in the Reading Room: The Influence of Fatigue in Radiology. Journal of the American College of Radiology: JACR 2016; doi:10.1016/j.jacr.2016.10.009

[25] Drew T, Evans K, Vo ML et al. Informatics in radiology: what can you see in a single glance and how might this guide visual search in medical images? Radiographics: a review publication of the Radiological Society of North America, Inc 2013; 33: 263 -274. doi:10.1148/rg.331125023

[26] Swensson RG. A two-stage detection model applied to skilled visual search by radiologists. Perception \& Psychophysics 1980; 27: 11-16. doi:10.3758/bf03199899 